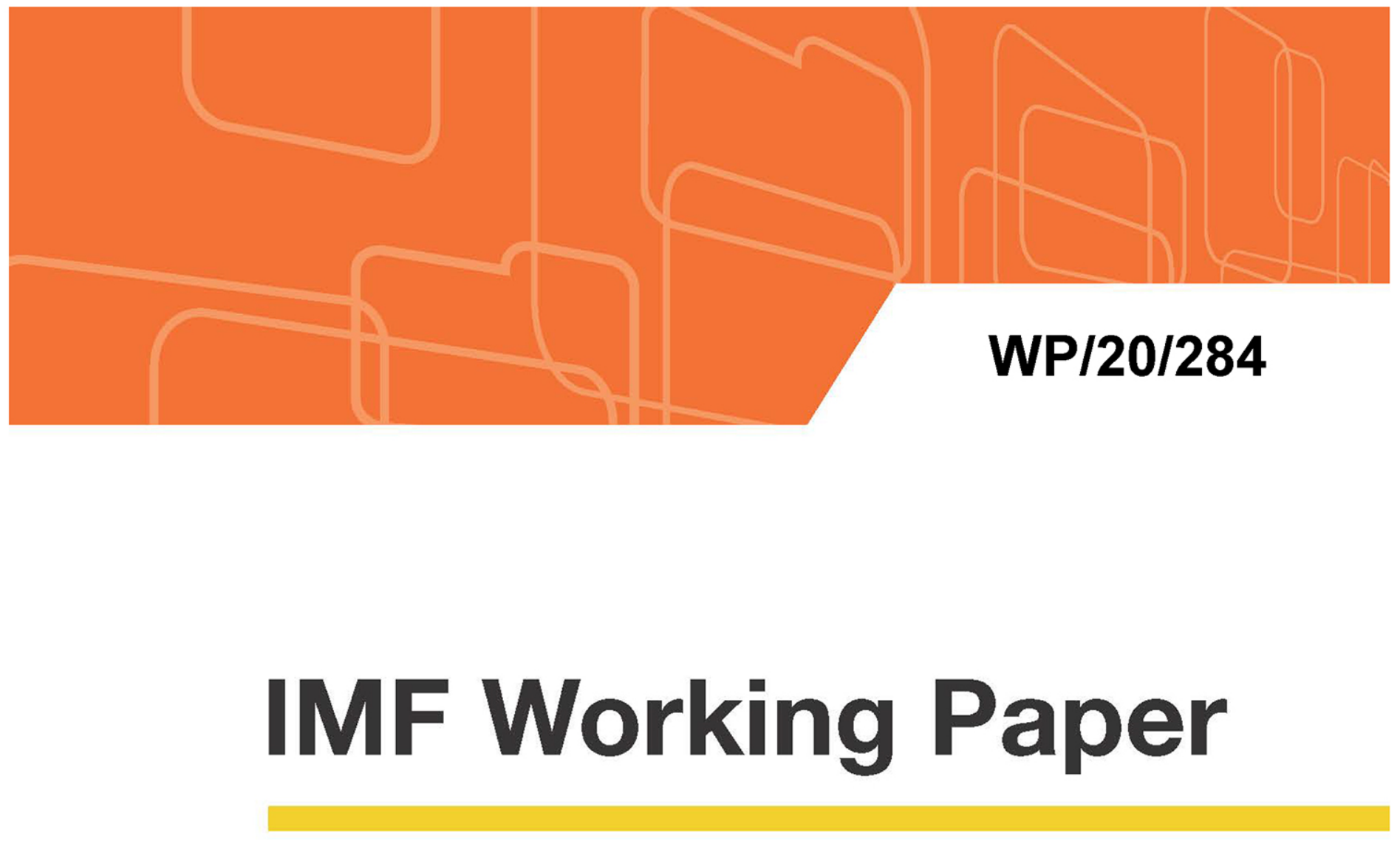

\title{
Supply Spillovers During the Pandemic: Evidence from High-Frequency Shipping Data
}

by Diego A. Cerdeiro and Andras Komaromi

IMF Working Papers describe research in progress by the author(s) and are published to elicit comments and to encourage debate. The views expressed in IMF Working Papers are those of the author(s) and do not necessarily represent the views of the IMF, its Executive Board, or IMF management. 


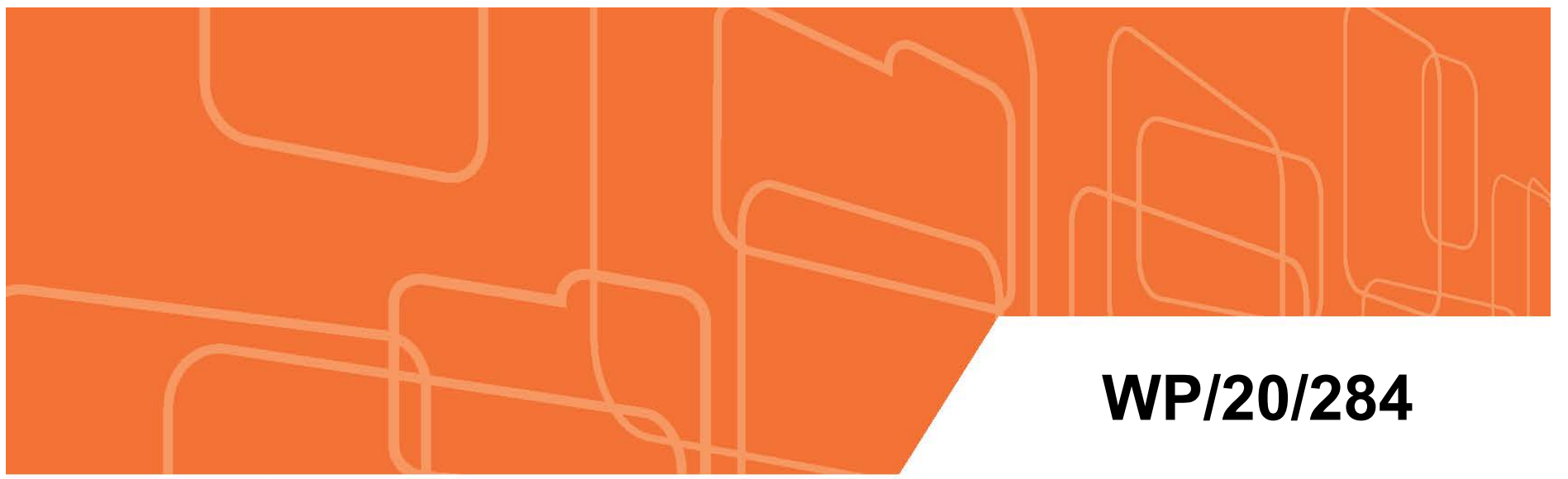

\section{IMF Working Paper}

\section{Supply Spillovers During the Pandemic: Evidence from High-Frequency Shipping Data}

by Diego A. Cerdeiro and Andras Komaromi

IMF Working Papers describe research in progress by the author(s) and are published to elicit comments and to encourage debate. The views expressed in IMF Working Papers are those of the author(s) and do not necessarily represent the views of the IMF, its Executive Board, or IMF management. 


\title{
IMF Working Paper
}

Asia and Pacific Department and Innovation Lab Unit

\author{
Supply Spillovers During the Pandemic: \\ Evidence from High-Frequency Shipping Data* \\ Prepared by Diego A. Cerdeiro and Andras Komaromi* \\ Authorized for distribution by Helge Berger and Tristan Walker
}

December 2020

\begin{abstract}
IMF Working Papers describe research in progress by the author(s) and are published to elicit comments and to encourage debate. The views expressed in IMF Working Papers are those of the author(s) and do not necessarily represent the views of the IMF, its Executive Board, or IMF management.
\end{abstract}

\begin{abstract}
World trade contracted dramatically during the global economic crisis induced by the COVID-19 pandemic. Disruptions in international supply chains were widely reported as governments imposed containment measures (lockdowns) to halt the spread of the disease. At the same time, demand declined as households and firms scaled back spending. This paper attempts to disentangle the supply and demand channels in trade by quantifying the causal effect of supply spillovers from lockdowns. We utilize a novel dataset of daily bilateral seaborne trade, and design a shift-share identification strategy that leverages geographyinduced cargo delivery lags to track the transmission of supply disruptions across space. We find strong but short-lived supply spillovers of lockdowns through international trade. Moreover, the evidence is suggestive of the downstream propagation of countries' lockdowns through global supply chains.
\end{abstract}

JEL Classification Numbers: F10, F14, F42, I18, R40

Keywords: COVID-19, lockdowns, trade, spillovers, supply chains.

Author's E-Mail Address: dcerdeiro@imf.org; akomaromi@imf.org

\footnotetext{
^ We are very grateful to Helge Berger, Joong Shik Kan, and Martin Kaufman for many helpful discussions. We also thank Fan (Mike) Zhang for kindly sharing his lockdown stringency index for China, and Davide Furceri for very detailed comments.

* Diego A. Cerdeiro: IMF, Asia and Pacific Department; Andras Komaromi: IMF, Innovation Lab Unit.
} 


\section{INTRODUCTION}

One of the distinctive features of the COVID-19 crisis is the confluence of sharp turns in supply and demand conditions as governments imposed strict lockdowns in tandem with households and firms scaling back spending. Quantifying the actual bearing of government containment measures on the evolution of global trade during the pandemic is crucial for debates about the role of supply disruptions during the global crisis, and whether trade and tax policies should be used to try to reshape global production (Goldberg, 2020). Leveraging a unique dataset of highfrequency estimates of seaborne trade, we propose a shift-share research design to quantify the supply spillovers of government measures aimed at containing the spread of the virus.

A rapidly growing literature has sought to quantify the effect of containment measures on domestic economic activity (see e.g. IMF, 2020; Deb, Furceri, Ostry and Tawk, 2020; Maloney and Taskin, 2020; Chen, Igan, Pierri and Presbitero, 2020). ${ }^{1}$ In contrast, and to the best of our knowledge, no paper has tried to gauge the international spillover effects of these measures. Although the effects of the crisis on cross-border transactions were widely reported in the press, ${ }^{2}$ data availability has constrained most empirical research to understanding domestic effects. We aim to fill this gap by using daily bilateral trade volume information and exploiting geographyinduced lags in how disruptions transmit across borders.

A country's imports during the pandemic are affected by the lockdown measures imposed by the country's partners that supply these goods. We thus propose and construct a measure of lockdown exposure to trace the effects of these supply-side disruptions. To estimate the effect of these disruptions on import growth, we rely on a unique dataset of daily estimates of bilateral trade volumes based on the radio signals that the world fleet of cargo ships emits for navigational safety purposes (Cerdeiro, Komaromi, Liu and Saeed, 2020). The high-frequency nature yields multiple sources of variation that allows identification of the causal effect. In particular, the variation in our data is not just due to different timing of lockdown measures (shift) and different import weights across countries (shares), but also due to the geography-induced lags in the transmission of lockdowns between countries.

\footnotetext{
${ }^{1}$ For a review of this literature, see Chapter 2 of the 2020 October World Economic Outlook (IMF, 2020) or Brodeur, Gray, Islam, and Bhuiyan (2020).

2 See, e.g., "World Economy Shudders as Coronavirus Threatens Global Supply Chains," Wall Street Journal, February 23, 2020; "US supply chains and ports under strain from coronavirus," Financial Times, March 2, 2020.
} 
Figure 1 illustrates our identification strategy. Because China was among the first countries to impose lockdown restrictions, a visual analysis of its initial effects is less likely to be affected by confounding factors, and therefore more amenable to a simple illustration. The top two panels in Figure 1 show the distribution of travel times in our bilateral seaborne trade dataset from China to Korea (left panel) and from China to the U.S. West Coast (right panel). With most trips taking between one to three days, the lockdowns imposed by China on January $23^{\text {rd }}$ (red vertical line in bottom two charts of Figure 1) very soon raised our measure of lockdown exposure for Korea. Korean import growth fell significantly in the wake of this sudden increase in the country's lockdown exposure. A similar pattern is observed for the U.S. West Coast, where the modal travel time from China is of around two weeks. Overall import growth also fell significantly in the U.S. as the strict containment measures imposed by China on January $23^{\text {rd }}$ kicked in the region's lockdown exposure. Of course, these are only two countries in our sample, and even in these simple examples there are various possible confounding factors. To claim identification, we develop a rigorous shift-share regression design with appropriate control variables.

Figure 1. Lockdown Exposure and Import Growth: The cases of Korea and the U.S.
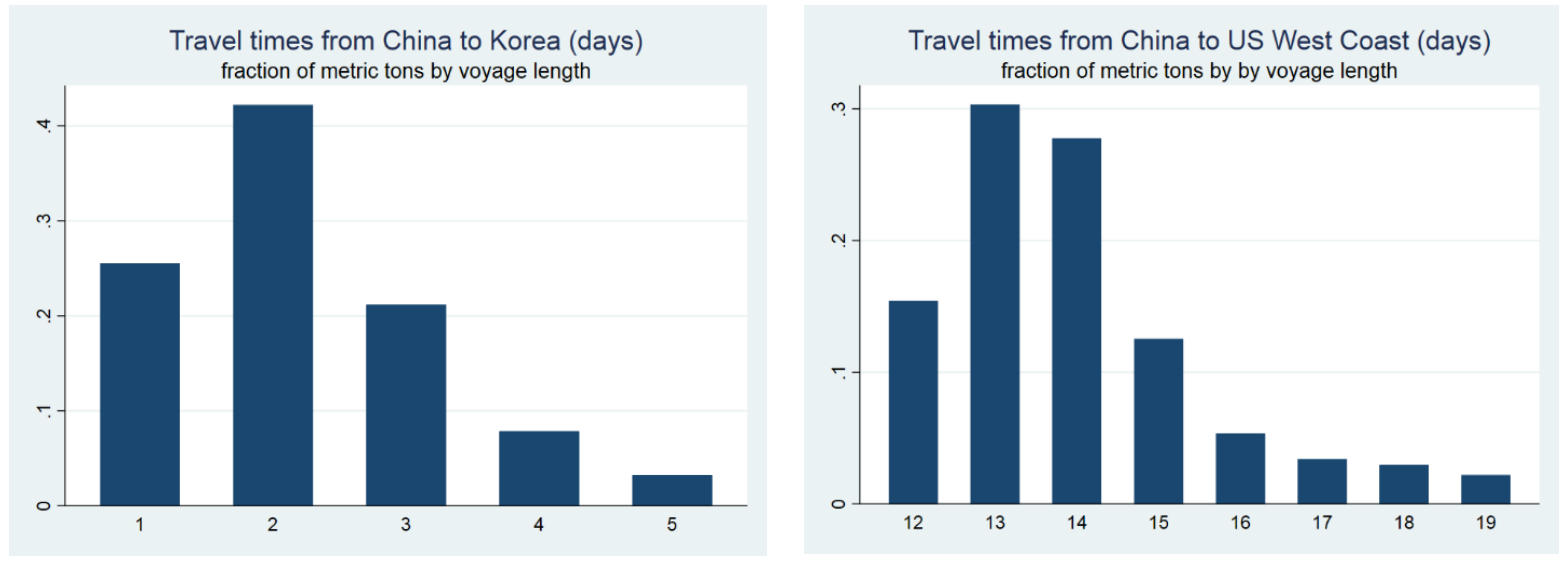

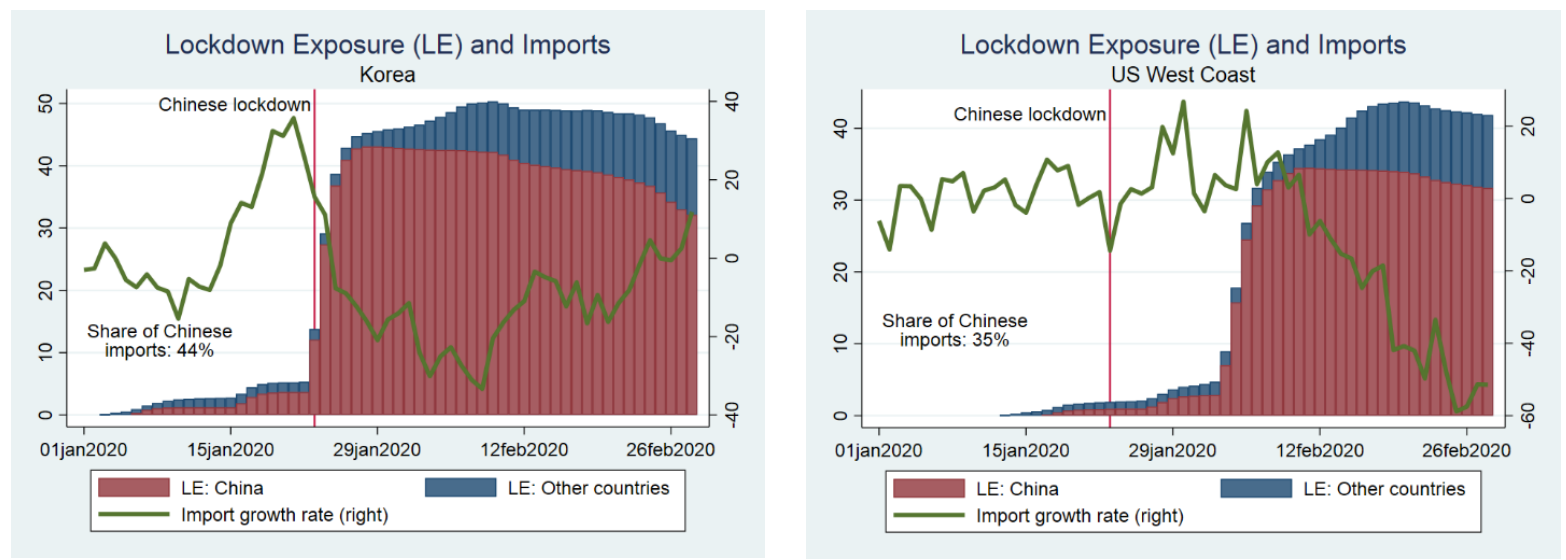

Our empirical analysis finds very strong but short-lived trade spillovers from supply disruptions due to lockdowns. Our preferred estimate over the entire sample implies that in a hypothetical case where all of a country's suppliers went from no lockdown to a full lockdown would lead to more than 20 percentage points drop in the country's seaborne import growth. This estimated spillover effect, however, is especially large and statistically significant in the early stages of the crisis - explaining about 10 percent contraction of world trade in February-March -, and it becomes statistically insignificant later in the sample. The short-lived nature of disruptions despite the shock being unprecedented in scale - adds to existing arguments in support of globalized production on the grounds of efficiency and diversification benefits (see e.g. Bonadio, Huo, Levchenko and Pandalai-Nayar, 2020; Van Tongeren, 2020).

We also explore the possibility that the effects of lockdowns reverberate indirectly through supply chains guided by earlier results from the literature on the transmission of shocks through production networks (Acemoglu, Akcigit and Kerr, 2016). Specifically, a lockdown in country $A$ may indirectly affect a country $C$ if, for example, $A$ supplies inputs that are necessary for a country $B$ to export to $C$. We propose an extension of our specification to evaluate this possibility. Various factors make identification in this case more challenging, and strong assumptions are needed to take the model to the data, including due to possibly-heterogeneous processing lags across ports and an intrinsic difficulty in identifying the right weights to construct indirect lockdown exposures. We argue that these assumptions are likely to bias our estimates toward not finding indirect supply-chain effects from lockdowns. Despite this, we find that during the early stages of the crisis both direct and indirect supply-chain effects are marginally significant and economically sizeable, and we strongly reject the hypothesis of joint 
non-significance of direct and indirect supply-chain effects. The results are suggestive of the downstream propagation of countries' lockdowns through global supply chains.

The rest of the paper is organized as follows. Section II lays out the shift-share design underlying our empirical estimates. Section III summarizes how the high-frequency dataset was constructed, presents other data sources, and discusses the construction of key regressors. Section IV presents the results from our baseline specification. Section V shows the results of an extension of the model that accounts for indirect supply-chain effects. Section VI concludes.

\section{A SHIFT-SHARE DESIGN ON HIGH-FREQUENCY TRADE DATA}

Our empirical specification has an interpretation as a shift-share research design following Bartik (1991). We study the impact of a set of aggregate shocks or "shifters" on units differentially exposed to them, where the exposure is measured by a set of weights or "shares". Our units are countries that are differentially exposed to lockdown measures in other countries due to the heterogeneity in pre-existing trade connections.

Specification. Let $\widehat{M}_{i t}$ denote year-on-year import growth in country $i$ on day $t$. We want to identify the supply spillover effect that foreign governments' lockdowns may have had on this import growth. Let $l_{j, t}$ be the stringency of lockdown measures in country $j$ and on day $t$. Further let $w_{i, j}$ denote the pre-COVID fraction of imports into country $i$ that come from country $j$, and define $d(i, j)$ as the travel time in days from country $j$ to country $i$. Then, our empirical model can be written as:

$$
\begin{aligned}
& \widehat{M}_{i t}=\gamma_{t}+\alpha_{i}+\beta L E_{i t}+\mathbf{X}_{i t}^{\prime} \delta+\varepsilon_{i t}, \\
& L E_{i t}=\sum_{j} w_{i j} l_{j, t-d(i, j)}, \\
& \sum_{j} w_{i j}=1,
\end{aligned}
$$

where $\gamma_{t}$ and $\alpha_{i}$ are, time and country fixed effects, and $\mathbf{X}_{i t}$ includes control variables that may affect import growth and may be correlated with the lockdown exposures $\left(L E_{i t}\right)$.

Fixed effects and controls. To identify the effect of spillovers, the choice of control variables should ensure that the lockdown exposures $\left(L E_{i t}\right)$ are orthogonal to omitted factors $\left(\varepsilon_{i t}\right)$. Conceptually, the main concern is that the spread of the virus not only triggers lockdown 
measures in trading partners but can also impact demand for imports through other channels. Note that the daily frequency and fine geographic disaggregation of our dataset facilitate identification, because many of the confounding factors are expected to work at a slower pace. Nevertheless, it is important to discuss and mitigate potential endogeneity problems.

Travel times are partially determined by the geographical distance between ports and virus outbreaks can also be clustered in space. Hence, proximity to other ports in virus hotspots is likely associated with both high lockdown exposure and a high number of current or expected local infections. Worsening local health conditions can reduce imports through channels that are unrelated to the containment measures of trading partners, such as depressed consumer confidence and voluntary isolation that dent import demand, or locally imposed lockdowns that, for example, disrupt the ability of domestic ports of receiving imports. Similar concerns apply to the exogeneity of the pre-COVID trade links insofar as there may be more trade between nearby ports as the gravity model suggests. These arguments highlight the importance of including indicators of domestic COVID intensity, and mandated lockdowns as controls. To address these issues, in practice we include the following variables among the controls: domestic COVID cases, domestic deaths (both in ratio to the domestic population), and the stringency of domestic lockdowns. ${ }^{3}$

Initial conditions in different regions of the world may also affect the propensity of (foreign) authorities to impose lockdown measures. For example, it is possible for governments in regions experiencing lower growth to be more reluctant to impose lockdowns. To control for these idiosyncratic factors that also affect imports and can be correlated with our foreign lockdown exposure measure, our specification includes country fixed effects.

The prevalence of containment measures can also be correlated with other relevant factors over the time dimension. For example, as the virus spreads and more countries go under lockdowns, rising health and economic uncertainty may boost households' precautionary saving, and revised

\footnotetext{
${ }^{3}$ It is worth noting that some potential endogeneity issues are tackled more directly by using import growth (rather than import levels) as dependent variable. In particular, the empirical gravity model of trade tells us that country $i$ 's import levels are determined by distance. Since distance also determines how quickly the virus could spread to country $i$, it also affects how consumers may adapt to news of neighboring outbreaks. The reasoning here in favor of the use of growth rates instead of levels echoes the arguments brought forward in a more general context by Goldsmith-Pinkham, Sorkin and Swift (2020; see specifically the discussion on p. 2588).
} 
expectations in financial markets may lead to a tightening of financing conditions. Both developments could dampen demand for imports. While these effects will not necessarily play out at the daily frequency, we include time fixed effects to control for common trends associated with these time-varying global factors.

In all, our preferred specification therefore includes the following controls and fixed effects: domestic lockdown stringency, (change in) domestic cases in ratio to population, (change in) domestic deaths in ratio to population, and country and time fixed effects. ${ }^{4}$

Sources of identification. Before moving on to the overview of the data source and variable construction, it can be instructive at this stage to spell out the sources of variation that enable identification. Identification comes from three separate sources, the first two of which are standard in the shift-share literature.

Time series variation at the daily frequency:

(1) evolution of lockdown policies $\left(l_{j t}\right)$ : the stringency of containment measures evolves over time, so even countries with identical trade shares and identical travel times will see changes in their lockdown exposure.

Cross-sectional variation across countries:

(2) heterogeneity in pre-COVID trade shares $\left(w_{i j}\right)$ : countries that historically imported more from areas with stricter COVID containment measures will have higher effective lockdown exposure.

(3) heterogeneity in travel times $(d(i, j))$ : countries that are closer to areas with stricter COVID containment measures will face higher effective lockdown exposure sooner.

While (1) and (2) are standard sources of identification in shift-share regressions, (3) is unique to our problem and dataset. It is unique to our problem because seaborne trade inherently involves meaningful differences in delivery lags from the same origin to different destinations. It is

\footnotetext{
${ }^{4}$ We also further investigate our results through ancillary specifications that add COVID cases and deaths in trading partners as additional controls. While not very likely, the inclusion of foreign disease variables could aid identification in cases where foreign production is affected by voluntary decisions not to report to work despite the absence of government-mandated lockdowns.
} 
unique to our dataset because standard sources for bilateral trade data are at best at a monthly frequency that is too low to allow for adequate identification.

\section{HIGH-FREQUENCY DATA AND VARIABLE CONSTRUCTION}

This section describes the data sources and explains how the different variables included in the specification were constructed.

\section{A. High-frequency world seaborne trade dataset: Background}

More than $80 \%$ of merchandise trade by volume and $70 \%$ by value is carried by the world vessel fleet (UNCTAD, 2017). Much like airplanes and their transponders, for navigational safety purposes virtually all cargo ships in the world are required to carry a device commonly known as AIS (Automatic Identification System) that periodically emits a signal. ${ }^{5}$ The radio messages emitted by these devices - which include information about position, speed, draught, etc. - are visible to nearby ships so as to avoid collisions, and are also collected by terrestrial receivers (if the ship is near a shore) and commercial satellites (if the ship is in the deep oceans).

Cerdeiro, Komaromi, Liu and Saeed (2020; CKLS henceforth) show how different machinelearning techniques can be used to construct port-to-port voyages and estimates of trade volumes based on AIS data. We use their estimates that build on over one billion AIS messages collected between January $1^{\text {st }} 2015$ and June $30^{\text {th }} 2020$. To make this paper self-contained, we briefly illustrate here the process of going from the raw AIS messages to port-to-port volume estimates. The reader is referred to CKLS for further details.

First, a spatial clustering algorithm is applied to all low-speed messages reporting navigational status anchored or moored to detect areas on the map that are presumed to be ports and using publicly available information these areas are mapped to ports and to countries. Second, a random forest classifier is trained using official U.S. vessel-level entry records to tell us, for any ship stepping on any of these port areas, whether this visit is related to trade or if the ship was simply passing by. Finally, trade volumes are calculated on the basis of draught information

\footnotetext{
${ }^{5}$ While most ships send AIS messages with a frequency of 2-10 seconds, the data we use are down-sampled to the hourly frequency. The raw AIS data were collected by MarineTraffic.
} 
contained in the messages, i.e. how deep the ship is into the water. The mapping of these volumes to imports, exports or intra-country trade is a function of the country where the previous and next ports are located, and the full sequence of draught values of the ship. The process is summarized in Figure 2. ${ }^{6}$

Figure 2. Construction of Port-to-Port Trade Volumes from AIS data

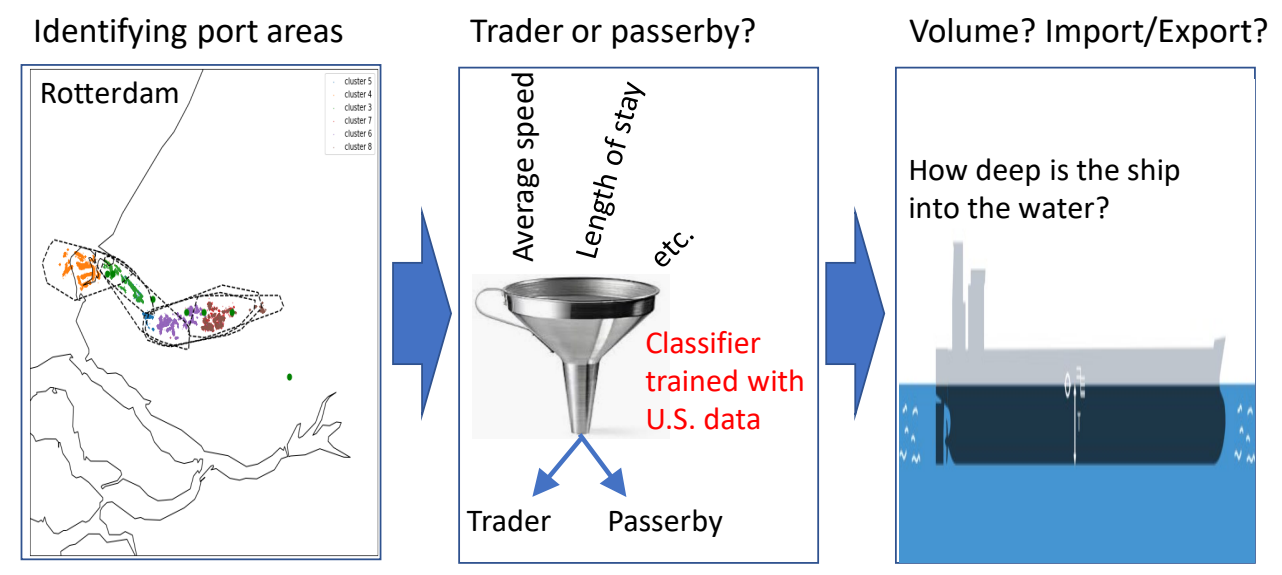

Notes: The Figure illustrates the end-to-end solution to go from raw AIS data to port-to-port trade volumes. See Cerdeiro, Komaromi, Liu and Saeed (2020) for full details.

Throughout the paper, the bilateral data are aggregated to the country-pair level except for the U.S. Given the very different travel times from/to different U.S. coasts, U.S. ports are grouped into two regions (U.S. West and U.S. East). We also focus only on non-commodity trade (general cargo, container ships, and vehicle carriers).

Finally, we take two steps to reduce noise in the data. First, small countries tend to receive ships very infrequently, resulting in large and abrupt jumps in daily import growth rates. All our results are therefore based on the top 50 importing countries, which in aggregate account for the overwhelming majority of world trade volumes. Second, even for large countries the daily data are noisy, as one day can see many more incoming ships than adjacent days. We therefore use a 7-day moving average of the daily trade estimates. ${ }^{7}$ To further reduce idiosyncratic volatility in

\footnotetext{
${ }^{6}$ The country-level aggregated trade volume estimates can be visualized at https://comtrade.un.org/data/monitor and downloaded at https://comtrade.un.org/data/ais.

${ }^{7}$ The moving-average transformation mechanically introduces autocorrelation in our error term - e.g. any ship arriving unexpectedly at time $t$ will reverberate in our transformed data for six additional days. Econometrically, we address the resulting inference problem by clustering standard errors at the country-level which are robust to autocorrelation.
} 
our data, we calculate daily growth rates for 2020 by taking the average of the same dates in the previous three years (2017-19) as the base period. Defining the base period this way also mitigates problems with shifting trade patterns in 2019 because of U.S. tariffs and their retaliatory counterparts.

\section{B. Overview of high-frequency cargo data}

The main interest in CKLS is to nowcast trade volumes at the country level. As a result, CKLS include an in-depth analysis of country-level estimates of trade volumes. In contrast, the spillover analysis of the present paper requires the use of bilateral trade estimates. We therefore deem necessary to briefly describe here some features of the bilateral data that are relevant for our purposes.

Table 1 shows the estimated metric tons of imports for the top 50 countries considered in the analysis, estimated using AIS data since April $1^{\text {st }} 2015 .{ }^{8}$ In aggregate, these countries account for 87 percent of the estimated global non-commodity imports by weight. The top 3 importers are in Asia, the center of the world's largest regional supply chain. Major importing hubs in Europe the UK and the Netherlands - are also present in the top 10. The ports of the U.S. East coast rank $5^{\text {th }}$ and receive significantly larger volumes than U.S. West ports, which altogether as a region are ranked $12^{\text {th }}$. Combined, U.S. East and U.S. West would be ranked at number 2. In all, the top 50 regions cover economies across Africa, America, Asia and Europe.

\footnotetext{
${ }^{8}$ While the raw-AIS data sample starts on January $1^{\text {st }}, 2015$, the classification of a port call as imports requires knowing that the previous port is in fact located in a different country. To avoid start-point estimation problems, we censor our estimates before April ${ }^{\text {st }}, 2015$.
} 


\section{Table 1. Top 50 Importers by 2015-2019 Import Volume}

\begin{tabular}{|c|c|c|c|c|c|c|c|}
\hline Rank & Region & $\begin{array}{l}\text { Millions of } \\
\text { metric tons } \\
\text { of imports }\end{array}$ & $\begin{array}{c}\text { Cumulative } \\
\text { world } \\
\text { share }\end{array}$ & Rank & Region & $\begin{array}{l}\text { Millions of } \\
\text { metric tons } \\
\text { of imports }\end{array}$ & $\begin{array}{c}\text { Cumulative } \\
\text { world } \\
\text { share }\end{array}$ \\
\hline 1 & China & 571.0 & 8.3 & 26 & Morocco & 84.9 & 69.3 \\
\hline 2 & Singapore & 320.6 & 13.0 & 27 & France & 84.8 & 70.5 \\
\hline 3 & Korea & 287.4 & 17.2 & 28 & Greece & 80.9 & 71.7 \\
\hline 4 & United Kingdom & 287.3 & 21.4 & 29 & Thailand & 78.8 & 72.8 \\
\hline 5 & US East & 255.9 & 25.1 & 30 & Australia & 66.0 & 73.8 \\
\hline 6 & Japan & 249.4 & 28.7 & 31 & Sweden & 59.7 & 74.7 \\
\hline 7 & Netherlands & 213.3 & 31.8 & 32 & Israel & 58.4 & 75.5 \\
\hline 8 & Malaysia & 212.7 & 34.9 & 33 & Colombia & 55.6 & 76.3 \\
\hline 9 & Hong Kong SAR & 194.0 & 37.7 & 34 & Denmark & 51.1 & 77.1 \\
\hline 10 & United Arab Emirates & 189.4 & 40.5 & 35 & Bangladesh & 48.6 & 77.8 \\
\hline 11 & Taiwan Province of China & 166.5 & 42.9 & 36 & Portugal & 48.4 & 78.5 \\
\hline 12 & US West & 165.5 & 45.3 & 37 & Algeria & 46.9 & 79.2 \\
\hline 13 & Germany & 159.2 & 47.6 & 38 & Pakistan & 46.8 & 79.9 \\
\hline 14 & Turkey & 154.7 & 49.9 & 39 & Canada & 45.5 & 80.5 \\
\hline 15 & Spain & 143.7 & 52.0 & 40 & Egypt & 44.6 & 81.2 \\
\hline 16 & Italy & 138.6 & 54.0 & 41 & South Africa & 44.2 & 81.8 \\
\hline 17 & India & 138.5 & 56.0 & 42 & Nigeria & 43.9 & 82.4 \\
\hline 18 & Saudi Arabia & 135.2 & 58.0 & 43 & Russia & 43.2 & 83.1 \\
\hline 19 & Belgium & 115.8 & 59.7 & 44 & Malta & 42.5 & 83.7 \\
\hline 20 & Indonesia & 107.5 & 61.2 & 45 & Poland & 39.9 & 84.3 \\
\hline 21 & Brazil & 103.6 & 62.8 & 46 & Oman & 39.4 & 84.9 \\
\hline 22 & Vietnam & 94.3 & 64.1 & 47 & Norway & 39.4 & 85.4 \\
\hline 23 & Sri Lanka & 92.1 & 65.5 & 48 & Finland & 38.6 & 86.0 \\
\hline 24 & Mexico & 90.7 & 66.8 & 49 & Kenya & 35.1 & 86.5 \\
\hline 25 & Philippines & 86.3 & 68.0 & 50 & Peru & 34.1 & 87.0 \\
\hline
\end{tabular}

Notes: The Table shows the top 50 countries ranked by the estimated volume of non-commodity imports over 2015-2019 based on AIS data.

Table 2 shows the top routes in our dataset, ranked by the metric tons of imported cargo estimated through end 2019. While our dataset for non-commodity trade detects a total of 7,580 active routes over this period, the top 50 routes alone (i.e. $0.66 \%$ of all routes) account for 30 percent of non-commodity trade. Of the top 10 routes, 8 correspond to intra-Asia trade, only one is fully outside Asia (Netherlands to UK), and the remaining one is the route from China to the U.S. West Coast. 
Table 2. Top Routes by 2015-2019 Import Volume

\begin{tabular}{|c|c|c|c|c|c|c|c|}
\hline Rank & Route & $\begin{array}{l}\text { Millions of } \\
\text { metric tons }\end{array}$ & $\begin{array}{c}\text { Cumulative } \\
\text { world }\end{array}$ & Ran & Route & $\begin{array}{l}\text { Millions of } \\
\text { metric tons }\end{array}$ & $\begin{array}{c}\text { Cumulative } \\
\text { world }\end{array}$ \\
\hline 1 & from $\mathrm{CN}$ to $\mathrm{KR}$ & 153.5 & 2.0 & 26 & from GB to NL & 36.3 & 20.9 \\
\hline 2 & from $S G$ to $C N$ & 146.7 & 3.8 & 27 & from ES to IT & 35.9 & 21.3 \\
\hline 3 & from $\mathrm{CN}$ to JP & 89.6 & 5.0 & 28 & from $\mathrm{CN}$ to $\mathrm{VN}$ & 34.4 & 21.8 \\
\hline 4 & from $\mathrm{KR}$ to $\mathrm{CN}$ & 87.3 & 6.1 & 29 & from KR to USW & 34.3 & 22.2 \\
\hline 5 & from $\mathrm{HK}$ to $\mathrm{CN}$ & 81.4 & 7.1 & 30 & from $S G$ to $A E$ & 34.3 & 22.7 \\
\hline 6 & from $S G$ to $M Y$ & 74.6 & 8.1 & 31 & from TW to HK & 33.8 & 23.1 \\
\hline 7 & from $\mathrm{CN}$ to USW & 66.1 & 8.9 & 32 & from NL to $\mathrm{DE}$ & 32.4 & 23.5 \\
\hline 8 & from $\mathrm{NL}$ to $\mathrm{GB}$ & 66.0 & 9.8 & 33 & from $S G$ to $B R$ & 32.2 & 23.9 \\
\hline 9 & from SG to HK & 61.7 & 10.6 & 34 & from $K R$ to $M X$ & 31.8 & 24.3 \\
\hline 10 & from $M Y$ to $C N$ & 60.7 & 11.4 & 35 & from $O M$ to $A E$ & 31.7 & 24.7 \\
\hline 11 & from MY to IN & 57.9 & 12.1 & 36 & from $\mathrm{CN}$ to $\mathrm{PH}$ & 30.8 & 25.1 \\
\hline 12 & from JP to KR & 57.7 & 12.8 & 37 & from $A E$ to $S A$ & 30.6 & 25.5 \\
\hline 13 & from $M Y$ to $S G$ & 57.6 & 13.6 & 38 & from KR to USE & 30.0 & 25.9 \\
\hline 14 & from TW to $\mathrm{CN}$ & 54.7 & 14.3 & 39 & from $M Y$ to $A E$ & 29.8 & 26.3 \\
\hline 15 & from JP to CN & 52.5 & 14.9 & 40 & from USW to KR & 28.7 & 26.6 \\
\hline 16 & from $\mathrm{CN}$ to $\mathrm{HK}$ & 50.3 & 15.6 & 41 & from $\mathrm{CN}$ to $\mathrm{TH}$ & 27.9 & 27.0 \\
\hline 17 & from $\mathrm{CN}$ to TW & 47.2 & 16.2 & 42 & from $\mathrm{CN}$ to ID & 27.5 & 27.4 \\
\hline 18 & from $S A$ to $A E$ & 47.1 & 16.8 & 43 & from USW to JP & 27.4 & 27.7 \\
\hline 19 & from SG to ID & 46.4 & 17.4 & 44 & from TW to JP & 26.5 & 28.0 \\
\hline 20 & from $\mathrm{CN}$ to $\mathrm{SG}$ & 40.9 & 17.9 & 45 & from USW to TW & 26.5 & 28.4 \\
\hline 21 & from $R U$ to $T R$ & 40.4 & 18.4 & 46 & from $G B$ to $B E$ & 26.1 & 28.7 \\
\hline 22 & from IN to LK & 40.1 & 18.9 & 47 & from $C N$ to $M Y$ & 26.0 & 29.1 \\
\hline 23 & from $B E$ to $G B$ & 40.1 & 19.5 & 48 & from $M Y$ to $B D$ & 25.4 & 29.4 \\
\hline 24 & from $L K$ to IN & 37.8 & 19.9 & 49 & from $T H$ to $S G$ & 25.1 & 29.7 \\
\hline 25 & from $K R$ to JP & 36.5 & 20.4 & 50 & from SG to GR & 23.9 & 30.0 \\
\hline
\end{tabular}

Notes: The Table shows the top 50 routes ranked by the estimated volume of non-commodity imports over 2015-2019 based on AIS data. Economies represented by their respective ISO-2 codes, except: USW (U.S. West Coast), USE (U.S. East Coast).

When laying out the research design in Section II, we emphasized that a key source of variation that enables identification - the heterogeneity in travel times - is unique both to our problem and our high-frequency dataset. We argue that trying to estimate lockdown spillovers using standard sources of monthly bilateral trade data is likely to be elusive. Figure 3 aims to convey this intuition by showing the distribution of country-to-country travel times. The left panel in Figure 3 shows the empirical density of international travel times. Around $93 \%$ of all country-to-country voyages take place within a 30-day window. The right panel in Figure 3 shows, in turn, the volume of trade taking place under each different travel time. As can be readily seen, virtually all world seaborne trade is shipped and delivered within the month. As a result, daily trade data are 
crucial in order to identify the effects of lockdown policies that can be changed at an equallyhigh frequency.

\section{Figure 3. The Distribution of Travel Times in Shipping}
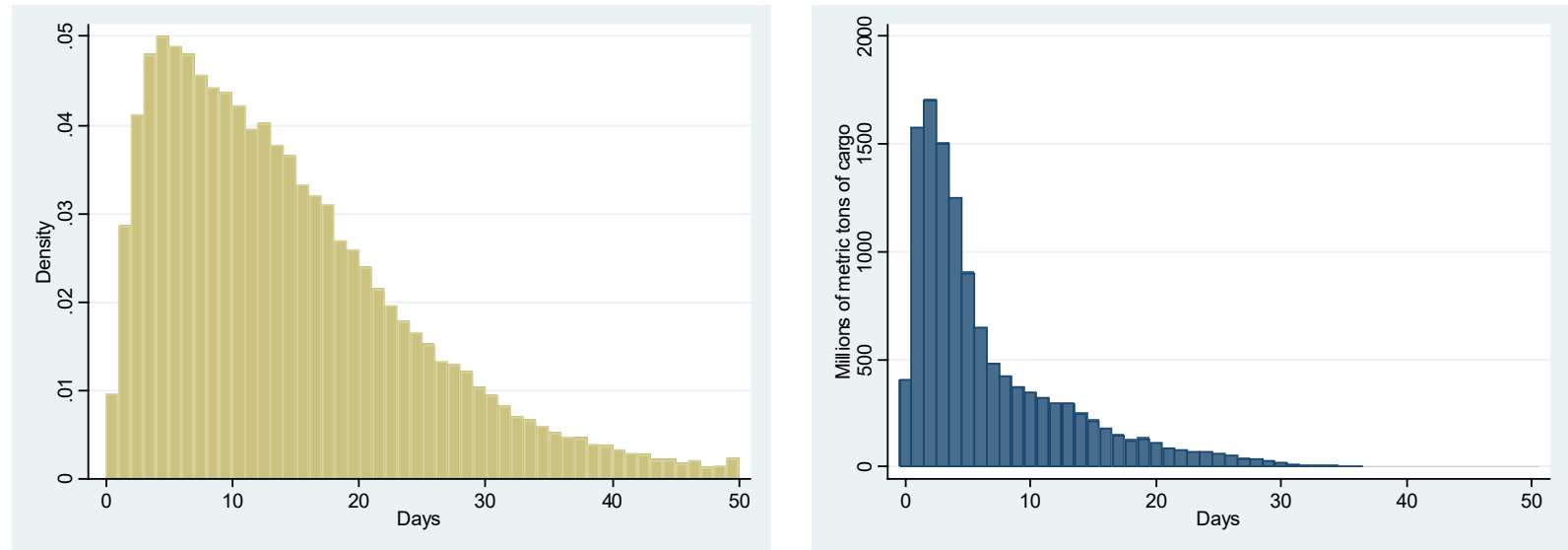

Notes: The left-hand-side panel shows the empirical distribution of country-to-country travel times. The right-handside panel shows the global volume of trade aggregated by the number of days involved in the corresponding country-to-country voyage.

\section{Lockdown intensity and disease-spread data}

Lockdown stringency and disease spread data are from Hale, Angrist, Kira, Petherik, Phillips and Webster (2020). Hale et al.'s lockdown stringency index is constructed as a simple average of nine different ordinal indicators designed to quantify the intensity of governments' responses aimed at containing the spread of the virus by restricting "people's behavior." Of the nine ordinal indicators, eight refer to closures and containment (school closures, workplace closing, cancelation of public events, restrictions on gatherings, closures of public transport, stay-at-home requirements, restrictions on internal movement, and international travel controls), and one records a health measure (public information campaigns). All nine indicators take integer values, with a maximum possible value of 4 . The resulting stringency index is then normalized such that it takes values from 0 (no restrictions) to 100 (the most stringent lockdown possible). ${ }^{9}$

\footnotetext{
${ }^{9}$ The data are available at https://covidtracker.bsg.ox.ac.uk/. For China, we use an updated version of the lockdown stringency index presented in Zhang (forthcoming). This paper broadly follows the data sources and methodology of
}

(continued...) 
We also rely on the daily series of confirmed COVID cases and confirmed deaths from the dataset by Hale et al. These underlying disease-related series are originally compiled by the European Centre for Disease Control.

\section{Time-to-delivery and variable construction}

In the empirical model above, we assumed that the travel time between two countries is a single number given by $d(i, j)$ (see eq. (2)). In reality, even for identical ships the travel time between two ports may vary (e.g. due to weather conditions). That is, $d(i, j)$ should not be interpreted as a scalar, but rather as a random variable whose distribution we can estimate from the historical data. Let $f_{i j}(d)$ denote the estimated probability mass function of the travel time from country $j$ to country $i$ :

$$
f_{i j}(d) \equiv \operatorname{Prob}[d(i, j)=d]
$$

Then, from the perspective of country $i$ 's imports from country $j$ on day $t$, the average lockdown stringency can be defined as:

$$
\bar{l}_{i j t}=\sum_{d=0}^{\infty} f_{i j}(d) l_{j, t-d}
$$

and the formula for the aggregate lockdown exposure of country $i$ changes to

$$
L E_{i t}=\sum_{j} w_{i j} \bar{l}_{i j t}
$$

In order to drop extreme values, we truncate the empirical distribution of the $d(i, j)$ travel times by leaving out, for each country pair, values below the $10^{\text {th }}$ and above the $90^{\text {th }}$ percentile.

To adequately aid identification of the effect of lockdown exposure, control variables also need to account for geography-induced delivery lags. Just as the effects of foreign lockdowns take time to materialize due to distance, controls need to account for potential confounding factors $a t$ the time when these incoming ships set sail from the ports of origin. ${ }^{10} \mathrm{With}$ the obvious exception

Hale et al. (2020) but derives province-level stringency indices which are then aggregated to the national level. Since Chinese lockdowns varied substantially across provinces, this bottom-up index better captures the evolution of average lockdown intensity in China.

${ }^{10}$ A stark illustration of the type of problem that could arise if these lags were not accounted for is ports in the U.S. and Europe being flooded with goods in April 2020 due to orders placed before demand conditions significantly deteriorated as the virus started spreading in those regions. See e.g. "European ports and warehouses brace for surge in containers," Financial Times, April 12, 2020. 
of the fixed effects, all our control variables are therefore also measured based on the empirical distribution of $d(i, j)$ and the import weights of partner countries. That is, if $x_{i t}$ denotes the observed value of a control variable for country $i$ at time $t$, then the regressor we include in practice is:

$$
\tilde{x}_{i t}=\sum_{j} w_{i j}\left(\sum_{d=0}^{\infty} f_{i j}(d) x_{i, t-d}\right)
$$

\section{RESUlTS}

\section{A. Main results}

Table 3 presents the estimates of the effect of lockdown measures on import growth. The variable Domestic lockdown refers to the restrictions imposed by local authorities, while Foreign lockdowns captures the exposure to containment measures in the country's trading partners. To interpret the results, recall that both domestic and foreign lockdowns are measured on a scale from 0 (no restrictions) to 100 (strictest possible lockdown).

The first column of Table 3 shows that going from no restrictions to a full lockdown in the local economy is associated with 10.5 percentage point lower import growth. Such a large association between domestic lockdowns and imports is consistent with the findings of Deb, Furceri, Ostry and Tawk (2020). When only including our foreign lockdown exposure measure (column (2)), we find that all suppliers of a country simultaneously going from no restrictions to a full lockdown is associated with 15.8 percentage point lower import growth.

When controlling for both domestic and partners' lockdown stringencies (column (3)), the coefficient on foreign lockdown exposure remains large and negative while the one on domestic lockdown becomes insignificant. This suggests that supply spillovers from trading partners may have a more clear-cut impact on imports than local lockdowns. These results remain remarkably stable as we subsequently include time (column (4)) and country (column (5)) fixed effects.

Our preferred specification is shown in column (6), where we further control for the number of confirmed COVID-19 cases and deaths in ratio to countries' populations. The coefficient on foreign lockdown exposure in this specification suggests that all partners going from no lockdown to a full lockdown leads to a fall of 22.6 percentage points in import growth. While not statistically significant, the negative coefficients on domestic disease variables may speak to the 
detrimental demand effects of the pandemic, likely working through fear and falling consumer confidence.

In column (7) we check whether the spillover effect of lockdowns is robust to including the disease intensity of the countries supplying the imported goods. Our question is whether supply disruptions are related to (foreign) government-imposed lockdowns or voluntary behavioral changes such as firms and workers choosing to reduce activity beyond the stringency of official containment measures. We assume that these voluntary behaviors are driven by fear of contracting the disease, and we capture them through changes in confirmed cases and deaths.

The results in column (7) confirm that the supply disruptions are indeed captured by the lockdown exposure variable, while foreign disease variables do not appear to significantly affect import growth. It is worthwhile to put this result in the context of related research that investigated the relationship between domestic lockdowns and economic activity in the U.S. and Europe (Goolsbee and Syverson, 2020; Chen, Igan, Pierri and Presbitero, 2020). These papers attribute a milder impact to actual lockdown measures and highlight the role of disease intensity and observed mobility as the proximate causes of declining activity. In contrast to these papers, our analysis focuses on the supply and transportation of exported goods as opposed to overall activity in the domestic economy. Taken together, the evidence suggests that government lockdowns were important determinants for the supply of internationally traded goods, even if more of the local economic contraction can be explained by the fear-driven collapse of demand. In all, the notably consistent results in Table 3 speak to a sizable supply component in the evolution of trade during the first six months of the COVID-19 crisis as the lockdown decisions of suppliers seem to have had significant and economically meaningful spillovers on countries' import growth. The estimates further suggest that the supply disruptions in trading partners might have been a more important driver of imports than domestic lockdown measures. 


\section{Table 3. Lockdown Spillovers - Effect on Import Growth}

\begin{tabular}{|c|c|c|c|c|c|c|c|}
\hline & (1) & (2) & (3) & (4) & (5) & (6) & (7) \\
\hline Domestic lockdown & $\begin{array}{c}-0.105^{\star \star \star} \\
(0.0228)\end{array}$ & & $\begin{array}{c}0.0970 \\
(0.0690)\end{array}$ & $\begin{array}{c}0.0864 \\
(0.0775)\end{array}$ & $\begin{array}{c}-0.0304 \\
(0.0720)\end{array}$ & $\begin{array}{l}-0.0181 \\
(0.0750)\end{array}$ & $\begin{array}{c}-0.0192 \\
(0.0741)\end{array}$ \\
\hline Foreign lockdowns & & $\begin{array}{c}-0.158^{\star * *} \\
(0.0255)\end{array}$ & $\begin{array}{l}-0.261^{\star *} \\
(0.0781)\end{array}$ & $\begin{array}{c}-0.284^{\star *} \\
(0.105)\end{array}$ & $\begin{array}{c}-0.246^{\star * *} \\
(0.0682)\end{array}$ & $\begin{array}{l}-0.226^{* *} \\
(0.0715)\end{array}$ & $\begin{array}{l}-0.210^{\star *} \\
(0.0767)\end{array}$ \\
\hline D.Domestic cases & & & & & & $\begin{array}{l}-0.122 \\
(0.414)\end{array}$ & $\begin{array}{c}-0.0226 \\
(0.471)\end{array}$ \\
\hline D.Domestic deaths & & & & & & $\begin{array}{l}-6.406 \\
(4.065)\end{array}$ & $\begin{array}{l}-7.836 \\
(4.090)\end{array}$ \\
\hline D.Foreign cases & & & & & & & $\begin{array}{l}-0.702 \\
(0.755)\end{array}$ \\
\hline D.Foreign deaths & & & & & & & $\begin{array}{c}6.082 \\
(9.721)\end{array}$ \\
\hline Constant & $\begin{array}{c}3.588 \\
(2.086)\end{array}$ & $\begin{array}{l}5.772^{*} \\
(2.522)\end{array}$ & $\begin{array}{l}5.935^{\star} \\
(2.538)\end{array}$ & $\begin{array}{l}8.112^{*} \\
(3.170)\end{array}$ & $\begin{array}{l}8.115^{*} \\
(3.326)\end{array}$ & $\begin{array}{l}10.94^{* *} \\
(3.237)\end{array}$ & $\begin{array}{l}10.94^{* *} \\
(3.245)\end{array}$ \\
\hline Observations & 8869 & 8869 & 8869 & 8869 & 8869 & 8771 & 8771 \\
\hline Time FE & No & No & No & Yes & Yes & Yes & Yes \\
\hline Country FE & No & No & No & No & Yes & Yes & Yes \\
\hline
\end{tabular}

${ }^{*} 5 \%,{ }^{* *} 1 \%$ and, ${ }^{* * *} 0.1 \%$ significance. Standard errors are clustered by country.

\section{B. Time-varying spillovers and aggregate effects}

The estimated coefficient of -0.226 in our preferred specification (6) is not constant through the sample. Figure 4 shows the point estimate and confidence bands for the model in column (6) estimated over 60-day rolling windows. The effect of foreign lockdowns is economically very large, and statistically significant during the early stages of the crisis, hovering around -0.4 between mid-February and late March. By April, however, the effect dissipates, both in size and in significance. 


\section{Figure 4. Lockdown Spillovers: Strong but Short-Lived}

60-day rolling sample: $\mathrm{t}-30$ to $\mathrm{t}+29$, clustered standard errors

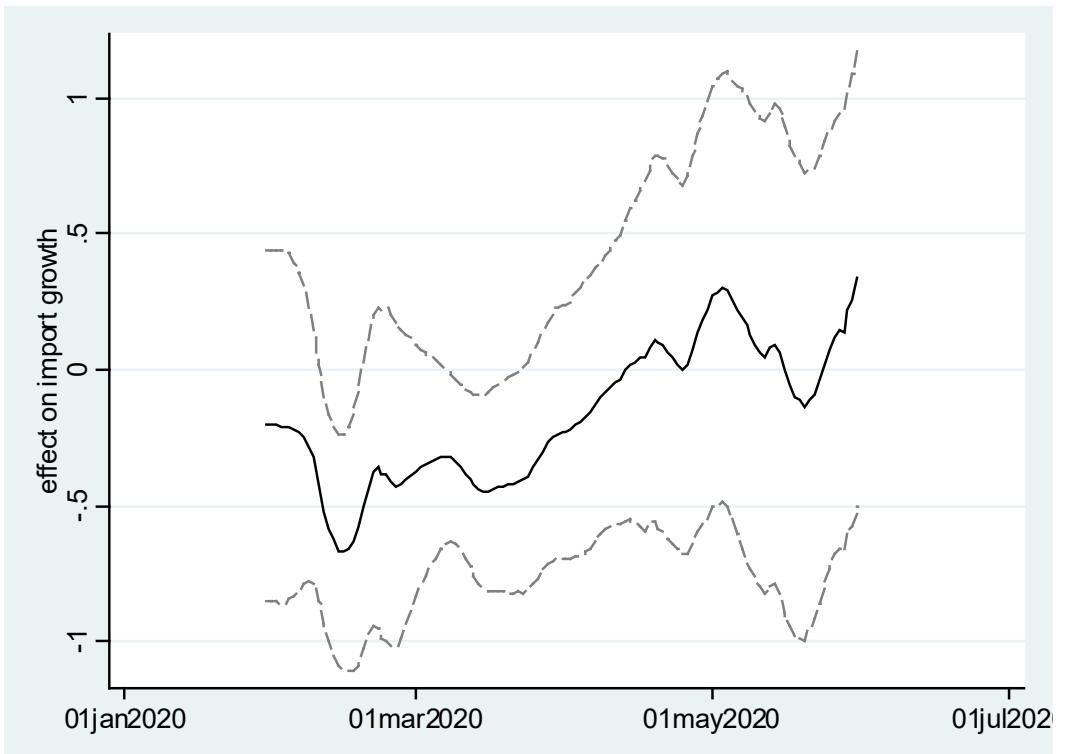

What could explain the vanishing lockdown spillovers in our empirical estimates? In any shiftshare design there is an assumption that general equilibrium effects are not pervasive in the given time frame, or in other words there are frictions preventing re-allocation after the shock. ${ }^{11}$ Consequently, in practice shift-share regressions test a joint hypothesis: the presence of frictions and the effect of the shock. The finding of an effect in the earlier part of our sample means that the frictions are large enough to trump any possible reallocation. Conversely, the absence of a statistically-significant effect toward the later part of our sample could be either because general equilibrium forces compensated any possible effects (i.e. supply chains reconfigured) or because the lockdowns imposed during that later period did not have an effect to begin with.

Empirically distinguishing these two explanations is challenging. Anecdotal evidence suggests that the early Asian lockdowns were qualitatively different from subsequent lockdowns in other parts of the world, which is hard to capture quantitatively in a stringency index. There may also be non-linearities at play where supply disruptions only kick in after a tipping point in lockdown

\footnotetext{
${ }^{11}$ In the credit-supply shock literature, where e.g. firms are exposed to banks, the underlying assumption is that it is hard to switch banks. If firms can easily switch lenders and banks could easily pick up demand for loans, then a shock to a few banks should have no aggregate effect. In the more trade-related work by Autor, Dorn and Hanson (2013), the units are commuting zones and industries, and the assumption is that labor cannot easily move across commuting zones and across industries. If workers could easily switch jobs, then the China shock could not possibly have large aggregate employment effects.
} 
stringency is achieved. ${ }^{12}$ The initial shock of Chinese lockdowns also triggered many discussions on how to make supply chains more flexible by building in redundancy and buffers. ${ }^{13}$ It is conceivable that 2-3 months was sufficient time for many firms to start re-configuring and adapting their supply chains to a more volatile environment. We leave it for future research to disentangle these possible channels.

Given strong evidence for trade spillovers of lockdowns in early 2020, it is natural to ask what these estimates imply for the evolution of world trade in the first stages of the pandemic. Our estimates can be readily used to compare observed import volumes with counterfactual volumes in the absence of foreign government lockdowns. The estimated effect of foreign lockdowns on import growth rates, $\beta L E_{i t}$, readily translates into an estimated effect in differences as $M_{i t-365} \hat{\beta} L E_{i t}$, where $M_{i t-365}$ is the base-period import volume. Counterfactual import volumes in country $i, M_{i t}^{c}$, can therefore be obtained as:

$$
M_{i t}^{c}=M_{i t}-M_{i t-365} \hat{\beta} L E_{i t} .
$$

Equipped with a value for $\hat{\beta}$ and the country-level, time-varying lockdown-exposure measures, it is then straighforward to obtain a counterfactual series for world import volumes. The same procedure can be used to isolate the effect of one specific country's lockdowns. Recall from (4) that $L E_{i t}=\sum_{j} w_{i j} \bar{l}_{i j t}$. The counterfactual effect on country $i$ 's imports due to one specific foreign country $j$ 's lockdown is obtained by using, in equation (5), $w_{i j} \bar{l}_{i j t}$ instead of $L E_{i t}$.

Figure 5 shows the resulting ratio of actual to counterfactual world trade through mid-March using a value of $\hat{\beta}=-0.4$. The Figure shows the effect of lockdowns around the world as well as the standalone effect of China's lockdown. The results imply that supply disruptions due to lockdowns, on average, reduced global seaborne imports in February-March 2020 by 10 percent, with China's lockdowns contributing about 4 percentage points.

\footnotetext{
${ }^{12}$ See e.g. "China's coronavirus lockdown strategy: brutal but effective," The Guardian, March 19, 2020

${ }^{13}$ See e.g. "Coronavirus Is a Wake-Up Call for Supply Chain Management," Harvard Business Review, March 27, 2020
} 
Figure 5. Ratio of Actual v. Counterfactual World Trade counterfactual with no lockdown-induced supply disruptions

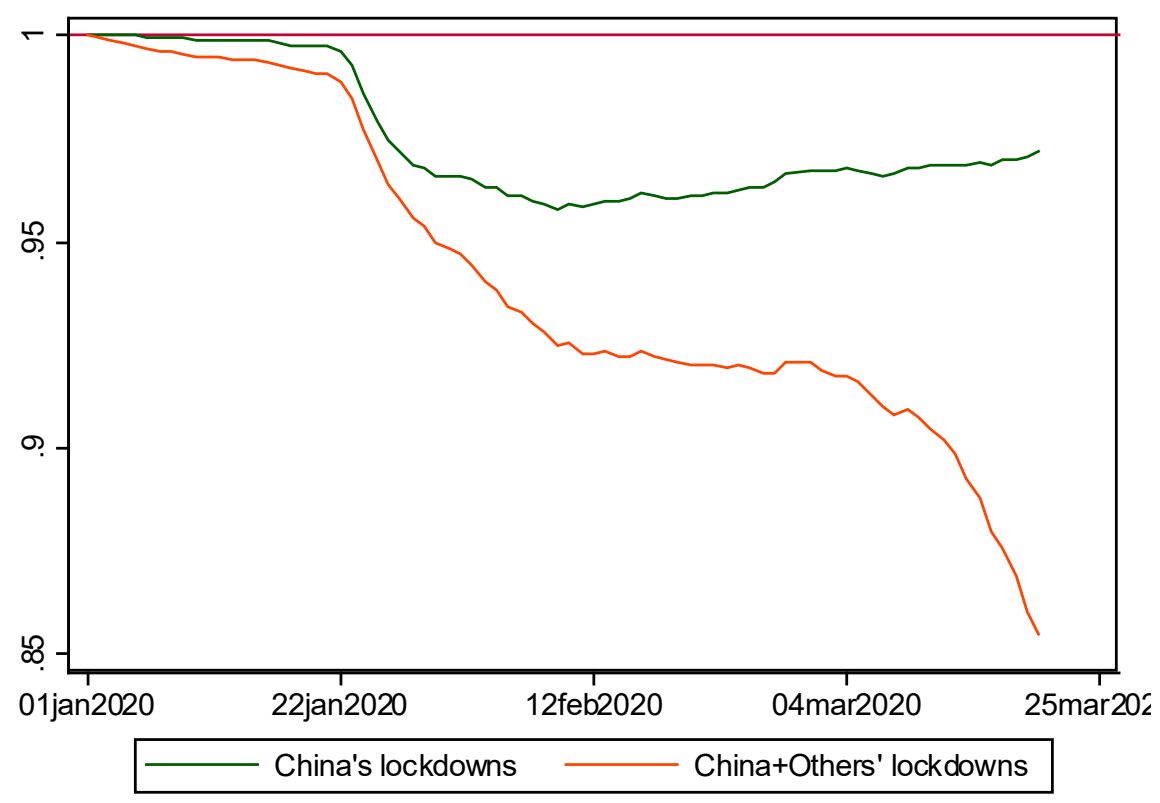

\section{INDIRECT SUPPLY-CHAIN EFFECTS}

Our main results show that, in the early stages of the crisis, supply disruptions significantly affected trade volumes. In this section we explore whether these supply shocks may have reverberated through indirect supply-chain linkages. The existing literature provides strong guidance on how these shocks should propagate. In particular, and as shown theoretically and empirically (based on U.S. input-output data) by Acemoglu, Akcigit and Kerr (2016), supply shocks propagate downstream. In what follows, we therefore extend the baseline model to account for indirect supply-chain linkages. We beging with an illustrative example, and then show the general formulation and discuss the assumptions that we make to take this formulation to the data.

\section{An illustrative example}

To fix ideas, consider a world economy where there are only three seaports, denoted China, Korea and the U.S. China exports to both Korea and U.S., and Korea only exports to the U.S. The U.S. does not export. Further assume the following travel times between ports: China to Korea 3 days, China to the U.S. 14 days, and Korea to the U.S. 11 days. We want to capture the spillover effects of Chinese and Korean lockdown policies on U.S. imports at daily frequency. 
With the assumptions made, China's lockdowns will have a direct impact on U.S. imports (via the direct route that connects China to the U.S.), and an indirect impact (as China may supply inputs used in the route that connects Korea to the U.S.).

As before, let $l_{j, t}$ denote the stringency of lockdown measures at port $j$ and on day $t$, and let $w_{i, j}$ denote the pre-COVID fraction of imports into port $i$ that come from port $j$. We can write U.S. import growth $\left(\widehat{M}_{U S, t}\right)$ as a function of direct lockdown exposure $\left(L E_{U S, t}^{1}\right)$, indirect lockdown exposure $\left(L E_{U S, t}^{2}\right)$ and other factors $\left(\varepsilon_{U S, t}\right)$ :

$$
\widehat{M}_{U S, t}=\beta_{1} L E_{U S, t}^{1}+\beta_{2} L E_{U S, t}^{2}+\varepsilon_{U S, t}
$$

Considering the travel times described above:

$$
L E_{U S, t}^{1}=w_{U S, K O R} l_{K O R, t-11}+w_{U S, C H N} l_{C H N, t-14} .
$$

$L E_{U S, t}^{2}$ is the indirect lockdown exposure, i.e. the lockdown exposure not of the U.S., but of the trading partners of the U.S. We define it recursively as

$$
L E_{U S, t}^{2}=w_{U S, K O R} L E_{K O R, t-11}^{1}+w_{U S, C H N} L E_{C H N, t-14}^{1} .
$$

That is, in our example, Korea's lockdown exposure at time $t-11$ is a relevant driver of U.S. imports at time $t$. The coefficient $\beta_{1}$ measures the direct spillover effect of lockdowns, whereas the coefficient $\beta_{2}$ measures the effects that act through global supply chains.

\section{Specification, assumptions, and results}

The empirical model behind the illustrative example can be written as:

$$
\begin{aligned}
& \widehat{M}_{i t}=\gamma_{t}+\alpha_{i}+\sum_{k=1}^{K} \beta_{k} L E_{i t}^{k}+\mathbf{X}_{i t}^{\prime} \delta+\varepsilon_{i t} \\
& L E_{i t}^{1}=\sum_{j} w_{i j}^{1} l_{j, t-d(i, j)} \\
& L E_{i t}^{k}=\sum_{j} w_{i j}^{k} L E_{j, t-d(i, j)}^{k-1} \text { for } k=2, \ldots, K \\
& \sum_{j} w_{i j}^{k}=1
\end{aligned}
$$

Here, $\mathbf{X}_{i t}$ includes the necessary control variables. This formulation includes higher order indirect exposures (e.g. $L E_{U S, t}^{k}$, for $k=2, \ldots, K$ ) that would capture long supply-chain links. We make three assumptions to take this model to the data. 
First, we take $K=2$. That is, we only go one step further than our baseline results and assume away any effect of lockdowns three and more steps away from the importing country. Given the short-lived nature of direct lockdown effects, especially in relation to global delivery lags involved in seaborne trade, our prior was that attempting to estimate higher order effects would be unlikely to yield precise estimates. This is confirmed by our results below, which show that even results for $K=2$ are only marginally significant at standard confidence levels.

Second, we further assume that $w_{i j}^{2}=w_{i j}^{1}$. In the illustrative example above, the lockdown exposures of the U.S. trading partners affect U.S. imports in proportion to the imports of the U.S. from these countries (i.e. the equation for $L E_{U S, t}^{2}$ uses the same weights as the equation for $\left.L E_{U S, t}^{1}\right)$. If, however, Korea's imports from China were all destined to final consumption, then Korea should not feature in $L E_{U S, t}^{2}$. In other words, the weights used to construct $L E_{U S, t}^{2}$ should ideally reflect higher-order input linkages. In the absence of data that could be used to construct such weights, we thus assume that $w_{i j}^{2}=w_{i j}^{1} \cdot{ }^{14}$

Finally, an implicit assumption in the illustrative example and the formal model is zero processing time of intermediate inputs. This is clearly not credible. When estimating indirect spillovers below, we impose homogeneous processing lags across countries and use the data to explore plausible lags.

Before moving on to the results, a discussion of how these assumptions could bias our results is warranted. While the assumption that $K=2$ is reasonable given the time-series dimension of the sample, the assumptions on equal direct and indirect weights $\left(w_{i j}^{2}=w_{i j}^{1}\right)$ and homogeneous processing times can introduce measurement error in our variables. However, there is no obvious a priori reason to believe that this error is systematically related to the true values. To the extent that this measurement error corresponds to the classical errors-in-variables case, the point estimates and t-statistics discussed below are actually biased downwards.

Panel (a) in Figure 6 shows the point estimate and confidence bands for the two main coefficients of interest, using different lags of indirect foreign lockdown exposure $L E_{i t}^{2}$ and estimating the model over the full sample. Both point estimates have the expected sign for every

\footnotetext{
${ }^{14}$ While input-output matrices could be used to construct higher-order weights, such weights would not necessarily correspond to input linkages embedded in trade that takes place by sea.
} 
processing time considered. Furthermore, the coefficient on indirect lockdown exposure exhibits an intuitive U-shaped pattern as we increase the number of days allocated to processing times. Even though we cannot pin down the duration of intermediate production steps a priori, the data confirms that it cannot be either too short or too long. While direct foreign lockdown exposure is significant for processing lags greater than around two weeks, indirect foreign lockdown exposure is not statistically significant in the full sample under any of the processing lags considered.

We therefore explore the estimates when focusing on the initial stages of the crisis, where earlier - in the main-result section - we found strong direct spillover effects. The point estimates and confidence bands for the two main coefficients of interest are shown in panel (b) of Figure 6. The U-shape of estimated indirect spillovers is even more pronounced in this sample with the maximum effect at around two-week processing lags. Despite the smaller sample, at two-week processing lags both the direct (p-value: 0.061 ) and indirect (p-value: 0.068 ) foreign lockdown exposures are marginally statistically significant at standard significance levels. In what follows we therefore focus the discussion on the results obtained in this sample.

\section{Figure 6. The Effects of Direct and Indirect Lockdown Exposures (LE) for different samples, and different indirect LE lags}

(a) Full sample

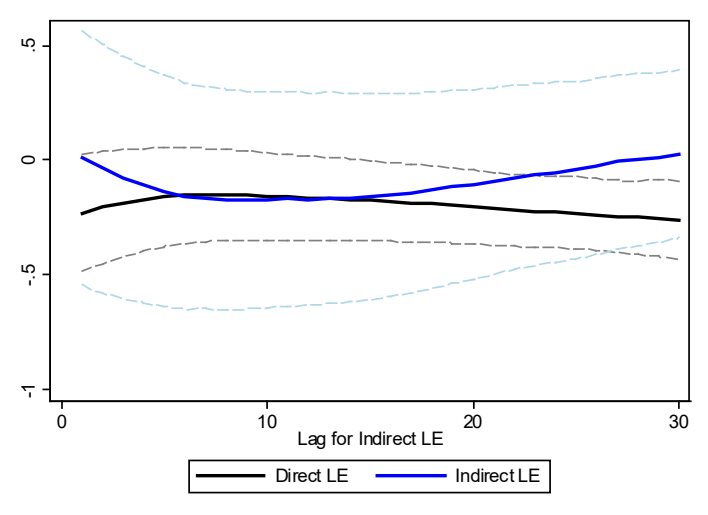

(b) Through March 31

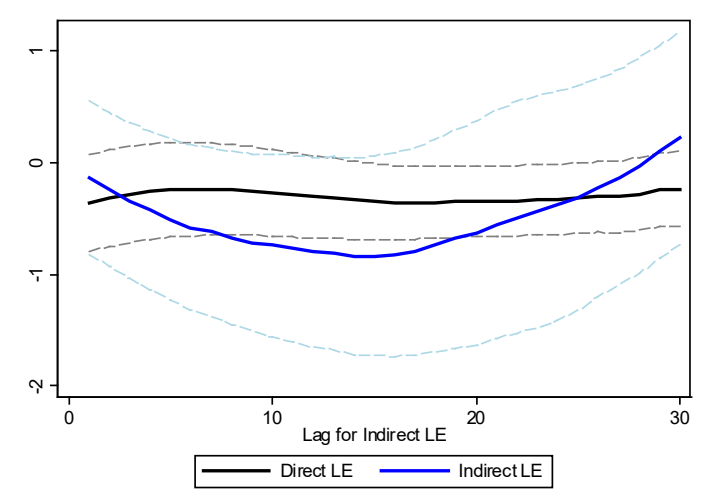

Notes: 95\% confidence bands, clustered standard errors. Lags in indirect LE exposure measure are used to account for processing times.

The first column in Table 4 reproduces our preferred specification estimated over the full sample (column (6) in Table 3 above). Column (2) adds the indirect foreign spillover measure based on a 
14-day processing lag, showing the negative but insignificant indirect lockdown effect in the full sample. ${ }^{15}$ As a benchmark, column (3) presents our preferred baseline specification estimated over the sample that goes through March 31. As shown in the discussion of our baseline results, the coefficient on direct lockdown exposure is both sizeable and statistically significant.

Column (4) in Table 4 adds the indirect lockdown exposure corresponding to the 14-day processing lag of Figure 6(b). As shown already in Figure 6, the point estimates on direct and indirect lockdown exposures are economically sizeable. While the point estimate on indirect lockdown exposure is larger, an F-test cannot reject the null that direct and indirect foreign lockdown coefficients are equal to each other (p-value: 0.3972). At the same time, the null that both coefficients are equal to zero is strongly rejected (p-value: 0.0011$)$. In all, the results are suggestive to the downstream propagation of countries' lockdowns through global supply chains.

${ }^{15}$ As we include a 14-day lag, we lose the first two weeks of observations. We checked that imputing zero indirect lockdown exposures before January 1, 2020 do not change the results in any meaningful way. 
Table 4. Direct and Indirect Lockdown Spillovers

indirect spillovers measured with 14-day processing lag

\begin{tabular}{lcccc} 
& $(1)$ & $(2)$ & $(3)$ & $(4)$ \\
\hline Domestic lockdown & -0.0181 & -0.00491 & 0.142 & 0.111 \\
& $(0.0750)$ & $(0.0836)$ & $(0.150)$ & $(0.160)$ \\
Foreign lockdowns & $-0.226^{* *}$ & -0.171 & $-0.433^{* *}$ & -0.351 \\
& $(0.0715)$ & $(0.0903)$ & $(0.155)$ & $(0.183)$ \\
& & & & \\
D.Domestic cases & -0.122 & -0.165 & $4.248^{*}$ & 3.595 \\
& $(0.414)$ & $(0.418)$ & $(1.830)$ & $(1.835)$ \\
& & & & \\
D.Domestic deaths & -6.406 & -6.353 & $-66.33^{* * *}$ & $-57.46^{* *}$ \\
& $(4.065)$ & $(4.113)$ & $(18.38)$ & $(18.07)$ \\
L14.Indirect lockdowns & & -0.163 & & -0.837 \\
& & $(0.232)$ & & $(0.448)$ \\
Constant & & & & \\
& $10.94^{* *}$ & 4.400 & $10.94^{* *}$ & 4.560 \\
& $(3.237)$ & $(3.526)$ & $(3.304)$ & $(3.406)$ \\
\hline Observations & 8771 & 8085 & 4312 & 3626 \\
Time FE & Yes & Yes & Yes & Yes \\
Country FE & Yes & Yes & Yes & Yes \\
Sample ends & June 30 & June 30 & March 31 & March 31 \\
\hline * 5\%, ${ }^{* *} 1 \%$ and, ${ }^{* * *} 0.1 \%$ significance. Clustered standard errors
\end{tabular}

\section{CONCLUDing REMARKS}

This paper implemented a shift-share research design on novel high-frequency bilateral trade data to uncover the origins of the marked trade collapse during the global COVID-19 recession. This period is often referred to as the Great Lockdown, because countries introduced unprecedented measures to reduce the movement and contact of citizens to contain the spread of the novel coronavirus. Lockdown measures led to major disruptions in the production and transportation of goods, which quickly spilled over to other countries through international supply chains. This prompted many observers to attribute most of the observed drop in trade to supply effects and to lockdowns in particular. At the same time, demand also dissipated on the back of increased risk aversion, revised income expectations and fear of the disease. The age-old question in economics resurfaced: Are the observed changes in trade volumes driven mostly by supply or demand effects? 
This paper separates the supply and demand channels in trade by constructing a measure of lockdown exposure to trace the effects of these supply-side disruptions. To estimate the spillover from one country's lockdown to other countries' import growth, we rely on a unique dataset of daily bilateral trade volumes estimated via tracking virtually all cargo ships in the world. This high-frequency data is key to our analysis, because it allows us to use geography-induced travel times to follow the transmission of lockdown shocks across the globe.

The results in this paper confirm that lockdowns and supply disruptions did play a significant role in the trade collapse - at least at the beginning of the crisis. Countries that historically had stronger trade links with and are closer to countries under heavy lockdowns experienced larger and faster contraction in their imports. We also find some evidence for indirect spillovers from lockdowns through global supply chains, as higher lockdown exposure of a country's trading partners is also associated with lower import growth. However, these spillover effects were only present during the first 2-3 months of the pandemic. After then, demand effects likely dominated the evolution of global trade.

Future research should investigate the underlying mechanism that produces the vanishing supply spillovers from lockdowns. We hypothize two possible explanations. It could be that frictions resolved within the timeframe of the analysis and firms were able to flexibly adapt their supply chains to the pandemic, including by finding new suppliers. Alternatively, it is possible that lockdowns imposed in the West in the later part of the sample were intrinsically different from early lockdowns imposed in Asia and Europe at the beginning of the sample.

\section{REFERENCES}

Acemoglu, Daron; Akcigit, Ufuk and Kerr, William. 2016. "Networks and the Macroeconomy: An Empirical Exploration," NBER Chapters, in: NBER Macroeconomics Annual, Volume 30, pages 273-335, National Bureau of Economic Research, Inc.

Autor, David H.; Dorn, David and Hanson, Gordon H. 2013. "The China Syndrome: Local Labor Market Effects of Import Competition in the United States.” American Economic Review, 103 (6): 2121-68. 
Bartik, Timothy J. 1991. "Who benefits from state and local economic development policies?" Kalamazoo, MI: Upjohn.

Bonadio, Barthélémy; Huo, Zhen; Levchenko, Andrei A. and Pandalai-Nayar, Nitya. 2020. "Global Supply Chains in the Pandemic," NBER Working Papers 27224, National Bureau of Economic Research, Inc.

Brodeur, Abel; Gray, David; Islam, Anik; Bhuiyan, Suraiya Jabeen. 2020. "A Literature Review of the Economics of COVID-19," GLO Discussion Paper, No. 601, Global Labor Organization (GLO), Essen

Cerdeiro, Diego A.; Komaromi, Andras; Liu, Yang and Saeed, Mamoon. 2020. "World Seaborne Trade in Real Time: A Proof of Concept for Building AIS-based Nowcasts from Scratch," IMF Working Papers 20/57, International Monetary Fund.

Chen, Sophia; Igan, Deniz O; Pierri, Nicola and Presbitero, Andrea F. 2020. "Tracking the Economic Impact of COVID-19 and Mitigation Policies in Europe and the United States," IMF Working Papers 20/125, International Monetary Fund.

Deb, Pragyan; Furceri, Davide; Ostry, Jonathan D. and Tawk, Nour. 2020. "The Economic Effects of COVID-19 Containment Measures," CEPR Discussion Papers 15087, C.E.P.R. Discussion Papers.

Goldberg, Pinelopi. 2020. “The New Empty Argument Against Trade,” Project Syndicate. May $12,2020$.

Goldsmith-Pinkham, Paul, Sorkin, Isaac and Swift, Henry. "Bartik Instruments: What, When, Why, and How," American Economic Review, Aug 2020, Vol. 110, No. 8 (pp. 2586-2624).

Goolsbee, Austan and Syverson, Chad. 2020. "Fear, Lockdown, and Diversion: Comparing Drivers of Pandemic Economic Decline 2020,” NBER Working Papers 27432, National Bureau of Economic Research, Inc.

Hale, T., N. Angrist, B. Kira, A. Petherik, T. Phillips and S. Webster. 2020. "Variation in government responses to COVID-19," Blavatnik School of Government Working Paper $2020 / 032$. 
IMF. 2020. "Chapter 2. The Great Lockdown: Dissecting the Economic Effects", In: World Economic Outlook: A Long and Difficult Ascent. Washington, DC, October

Maloney, William; Taskin, Temel. 2020. Determinants of Social Distancing and Economic Activity during COVID-19 : A Global View. Policy Research Working Paper;No. 9242. World Bank, Washington, DC.

United Nations Conference on Trade and Development (UNCTAD). 2017. "Review of Maritime Transport."

Van Tongeren, Frank. 2020. "Shocks, risks and global value chains in a COVID-19 world," OECD Trade and Agriculture Directorate, August 25, 2020.

Zhang, Fan .forthcoming. "China and the Great Lockdown." 